\title{
Pastoreo en áreas de montaña: Estrategias e impactos en el territorio
}

\section{Grazing in mountain areas: management strategies and territorial impacts}

\author{
Teodoro Lasanta*
}

\section{INTRODUCCIÓN}

Los sistemas ganaderos extensivos basados en el pastoreo afectan al 25\% de la superficie de la tierra, produciendo el 10\% de los alimentos consumidos por la población (FAO, 2001). Se distribuyen por ambientes naturales y culturales muy diversos, si bien las montañas constituyen áreas preferentes para su desarrollo.

Según Montoya (1984) el estudio de la ganadería extensiva requiere integrar pastizales y pastoreo como una unidad indisoluble, como único método para mejorar la gestión y productividad del ganado pastante. A la integración de pastizal y pastoreo, en sentido amplio, se denomina pastoralismo, término que procede del inglés (pastoralism) y que ha tenido una buena aceptación entre los profesionales e investigadores de la ganadería extensiva, tanto en España como en los países hispanoamericanos (Ferrer et al., 2001). Sin embargo, la Real Academia Española (RAE) no admite el término pastoralismo, por lo que en este trabajo se empleará normalmente el término pastoreo: «acción y efecto de pastorear el ganado», siendo pastorear «llevar ganado al campo y cuidar del mismo mientras pace» (RAE). Aún con todo acudiremos

\footnotetext{
*Instituto Pirenaico de Ecología (CSIC). Zaragoza (fm@ipe.csic.es).
} 
ocasionalmente al vocablo pastoralism para expresar un concepto más amplio que pastoreo, cuando - por ejemplo- se habla de efectos del pastoreo sobre el pasto o en el suelo.

Los estudios sobre ganadería extensiva y pastoralism ocupan un espacio destacado en la bibliografía sobre la montaña, con temas muy diversos entre los que cabe destacar: el papel de la ganadería en la explotación y conservación de los recursos, los desplazamientos del ganado a lo largo del año, la vinculación de los ciclos productivos a la disponibilidad de pastos y de mano de obra, la adaptación de las razas a las limitaciones del medio, y las relaciones entre ganadería, vegetación y erosión (Monasterio, 1980; Montoya, 1984; Montserrat y Fillat, 1990; Store, 1992). Una revisión bibliográfica, realizada en febrero de 2009, introduciendo el término pastoralism en la base de datos Scopus registraba 1366 citas. Una nueva incursión en la citada base el 16 de marzo de 2010 aportaba 1557 citas, referidas en su mayoría a áreas de montaña y medios áridos. El importante incremento de citas (un 14\% más) en poco más de un año demuestra el éxito del término pastoralism entre los investigadores preocupados por la ganadería extensiva y los pastos.

La razón por la que la ganadería de montaña ha atraído insistentemente a investigadores de muy diversas disciplinas es sencilla de explicar. Se trata de una actividad que ha desempeñado funciones de primer orden: social, económica, ecológica y de ordenación del territorio, dejando a lo largo del tiempo un fuerte sello cultural en la población y en el territorio, sobre todo en aquellas montañas en las que el ganado constituía la principal base económica (O'Connor, 1978; Montserrat y Fillat, 1977-78; Monasterio, 1980; Zorita, 1990; Sierra, 2002; Gibón, 2005).

En las páginas siguientes se describe la vinculación del pastoreo a las áreas de montaña, insistiendo en las estrategias de pastoreo (nomadismo, trashumancia y agropastoreo) y sus efectos sobre el medio, en la diversidad de razas y la complementariedad entre las especies ganaderas en el aprovechamiento de los pastos y la conservación de los recursos naturales. Se finaliza el trabajo apuntando algunos cambios recientes en el pastoreo de montaña. Para la realización de este trabajo se ha revisado la literatura científica incluida en Scopus. Además, se han consultado otras revistas, que incluyen con cierta frecuencia artículos sobre pastoreo, y varios libros publicados sobre gestión de las montañas. Por lo tanto, no se trata de una revisión bibliográfica completa, pero sí significativa para conocer los aspectos fundamentales del pastoreo y sus cambios recientes. 
¿QUÉ SE ENTIENDE POR PASTORALISM?

El pastoralism implica el consumo de pastos; en éstos se integran el conjunto de hierbas procedentes de pastizales (naturales, mejorados o sembrados) o de eriales, matorrales o bosques. También se incluyen entre los pastos cualquier otro tipo de malezas o frutos utilizables por el ganado, que aparecen en el territorio de forma dispersa y discontinua, por lo que no resulta rentable económicamente segarlas o recogerlas por el hombre.

Los pastos suelen distribuirse de forma heterogénea en el espacio y en el tiempo. Su aprovechamiento óptimo exige acudir, en el momento adecuado, con el ganado a los lugares donde se producen los máximos de producción y calidad (García-González, 2008). Este hecho, sencillo pero no simple, requiere disponer del ganado en el lugar donde y cuando se produce el alimento; en una cantidad o carga suficiente para consumirlo antes de su deterioro, con unas especies o razas animales capaces de aprovechar la mayor parte o la totalidad de la producción fotosintética y, de esta forma, contribuir a mejorarla. Además, es conveniente que el pastoreo no degrade el medio (erosión del suelo, empobrecimiento de pastos, simplificación de la estructura paisajística), ni interfiera con otros usos del mismo (producción agrícola, maderera, turismo,...). Todos estos condicionantes han propiciado que el pastoralism se desarrolle sobre todo en áreas muy frágiles para la explotación, como son las montañas y los medios áridos y semiáridos. No obstante, también el pastoralism aparece en áreas agrícolas, donde el ganado — sobre todo el ovino- aprovecha rastrojos, restos de cultivos y eriales intercalados entre los campos, dando lugar al agropastoreo (Hess, 1990; Uhlig, 1995; Molinillo y Monasterio, 1997; Lasanta y Errea, 1997; Gómez-Sal, 2001).

El pastoralism se ha definido como un modo de producción que aporta los productos necesarios para la subsistencia de las familias de los pastores, si bien con frecuencia afecta a toda la comunidad próxima (de Vries et al., 2006). Implica un proceso de adaptación a las condiciones naturales, tanto de los ganados, como de los pastos y de la sociedad (Browman, 1974). En los sistemas de pastoreo, los rebaños ocupan grandes extensiones del territorio, de forma permanente o con movimientos periódicos entre áreas de pastoreo en función de las necesidades económicas y ecológicas (Orlove, 1982). Todos estos rasgos propios del pastoralism hacen que se establezca una fuerte vinculación de la ganadería extensiva al medio físico. 
ÁREAS DE MONTAÑA Y PASTOREO

La importancia del pastoreo en áreas de montaña se justifica, sobre todo, por la abundancia de recursos de pastos y por las dificultades que el medio plantea para la agricultura intensiva. La altitud, la pendiente y la exposición, junto con la litología y las formas de relieve, determinan los principales rasgos ambientales y la distribución espacial de cubiertas y usos del suelo (Barry e Ives, 1974). La altitud implica una primera escala de diversidad, que se manifiesta en la presencia de varios niveles biogeográficos, morfoclimáticos y de usos del suelo; tales niveles se suceden desde la parte baja a la cumbre de cada montaña, ofreciendo recursos y potencialidades pastorales muy contrastadas. Además, dentro de cada nivel, la pendiente y la exposición originan microambientes muy distintos, contribuyendo a crear un mosaico de usos y cubiertas del suelo extremadamente complejo, en el que cada tesela constituye una unidad de paisaje con diferentes posibilidades de aprovechamiento (Balcells, 1985; García-Ruiz, 1990). En estas circunstancias resulta difícil alcanzar una fase intensiva de explotación (esencial para una agricultura competitiva), siendo las producciones escasas, y muy distribuidas en el espacio y en el tiempo (Puigdefábregas y Balcells, 1970). Por otro lado, una proporción elevada del territorio tan sólo es capaz de producir hierba o matorrales, recursos que pueden rentabilizarse exclusivamente mediante el aprovechamiento ganadero en pastoreo (García-Ruiz y Lasanta, 1987).

La explotación agrícola encuentra, pues, limitaciones (mucho más en sistemas económicos orientados al mercado que en los próximos al autoabastecimiento), mientras que la ganadera ofrece algunas ventajas. Por un lado, la movilidad del ganado permite el acceso a las distintas teselas sin gastos de transporte. Por otro lado, garantiza el aprovechamiento de los pastos en el momento de mayor producción o de mejor calidad. Lo más importante, sin embargo, es la capacidad que la ganadería tiene para transformar vegetales en proteínas animales, aprovechando recursos que de otra forma quedarían inutilizados (Le Houérou y Hoste, 1977; Granda y Prieto, 1986; Sierra, 1996). Por ello, no es extraño que en muchas áreas de montaña la ganadería extensiva haya sido (lo sigue siendo en no pocas) la principal actividad económica para la capitalización de sus habitantes y pueblos. La agricultura aportaba lo imprescindible para la subsistencia, mientras que el ganado ofrecía los productos vendibles al exterior y, por tanto, los ingresos económicos (White y Maldonado, 1991; Lasanta, 2002).

El ganado constituye, además, un elemento esencial para integrar los diferentes ecosistemas de la montaña; con sus desplazamientos transporta fertili- 
dad hacia los lugares más inaccesibles, asegurando no sólo la producción de estas áreas sino también la restitución de nutrientes a otras localizadas ladera abajo, con frecuencia utilizadas más intensivamente, tal y como han puesto de manifiesto Reffay (1967) en los Alpes, Osmaton (1985) en el Himalaya, y Puigdefábregas y Fillat (1986) en los Pirineos. Aún con todo, conviene resaltar que la agricultura ha tenido una enorme trascendencia en la mayor parte de las regiones de montaña, por muy fuertes que fuesen las limitaciones para su desarrollo, tanto para asegurar la alimentación de la población como para complementar la dieta del ganado (Lasanta, 1989).

A pesar de las ventajas de la montaña para el pastoreo también se plantean limitaciones. En primer lugar, hay que señalar que los prados y pastos productivos suelen ser escasos, localizándose básicamente en las áreas más fértiles y de suelo más profundo (Molinillo y Monasterio, 2001; Chocarro y Reiné, 2008). Por el contrario, dominan los recursos forrajeros considerados marginales desde una perspectiva economicista: matorrales, pastos bastos y especies poco apetecibles para el ganado (Flamant y Cocks, 1989; Vargas et al., 2002). En segundo lugar, pero no por ello menos importante, es necesario destacar el desequilibrio estacional en la oferta de pastos, derivado del acortamiento del ciclo vegetativo. Frente a una estación cálida - frecuentemente corta - capaz de alimentar a una cabaña ganadera muy numerosa aparece otra más dilatada en el tiempo con fuerte déficit de pastos (Lenclud y Pernet, 1978). Ferrer (1988) señala que en el Pirineo aragonés con los recursos estivales se puede alimentar una cabaña ganadera de 68.230 Unidades Ganaderas Mayores (UGM) durante 120 días, mientras que con los invernales sólo a 21.899 UGM.

\section{El PREDOMINIO DE SISTEMAS DE APROVECHAMIENTO VINCULADOS AL TERRITORIO}

El hombre ha utilizado estrategias muy diferentes para superar las limitaciones que introduce la montaña. Entre ellas destaca la implantación de sistemas de gestión extensivos; éstos se caracterizan por tratar de obtener la máxima producción con la mínima inversión y esfuerzo posibles, que en montaña es casi equivalente a sistemas pastorales o basados en el pastoreo (GarcíaRuiz y Lasanta, 1989). La estabulación de los animales y el transporte de alimentos hacia ellos (intensificación) es un sistema económico más caro y desde una perspectiva ecológica más costoso que un sistema basado en el pastoreo (García-González, 2008). En un régimen extensivo el ganado se alimenta casi exclusivamente de los recursos pascícolas, con reducido consumo de pienso en pesebre; requiere escasa inversión de capital y pocos cuidados en 
sanidad y vigilancia. Por el contrario, un sistema intensivo trata de obtener el máximo beneficio en el plazo más corto posible, lo que implica una rápida circulación del capital, una reducción progresiva de la mano de obra mediante la mecanización y automatización. Al mismo tiempo, ello supone siempre un gran aporte energético, es decir, consumo de energía fósil, un ajuste inmediato a las condiciones variables del mercado, una tendencia creciente a la estandarización del producto, una casi total independencia de las condiciones del medio y, una desatención a las consecuencias ecológicas a medio y largo plazo, y lo que podemos denominar cosificación del animal, o lo que es lo mismo la consideración del animal como un mero objeto o instrumento en el proceso de producción (Zorita, 1990). Desde un punto de vista económico, los sistemas extensivos ofrecen rentabilidades inferiores a los intensivos, si bien desde una perspectiva más amplia representan un esfuerzo humano decisivo para favorecer la diversidad de especies animales y vegetales, así como la estabilidad de los ecosistemas (Montserrat y Fillat, 2004).

La ganadería extensiva se apoya en la utilización directa de la diversidad productiva del territorio, lo que exige la presencia de varias especies de ganado y contar con ejemplares rústicos, capaces de transformar pastos abundantes pero de baja calidad (Celada et al., 1989). Son ya muy conocidas las ventajas que presenta el manejo de diferentes tipos de ganado en la estabilidad y productividad del pasto, al ser complementarios en el aprovechamiento de los recursos pascícolas (Montserrat, 1964 y 1976; McNaughton, 1985). A modo de ejemplo, se menciona la complementariedad entre vacunos, ovinos, caprinos y equinos. El tipo de dentición y la potencia bucal de los équidos facilita el consumo de las partes más fibrosas de las plantas; además su comportamiento en pastoreo le confiere virtudes limpiadoras al aprovechar precozmente las hierbas más bastas y menos apetecibles para el resto de las especies ganaderas. El cabrío tiene la facultad de desbrozar el matorral y consumir rebrotes altos, controlando el crecimiento arbustivo y contribuyendo a la apertura de itinerarios de pastoreo dentro de áreas de matorral cerrado; caballos y cabras componen, pues, un frente de protección y expansión del pastizal (Morley, 1981). La acción de vacas y ovejas sobre el pasto es complementaria por sus distintas apetencias pastorales; el vacuno selecciona poco, participando en el control de las herbáceas menos nutritivas. El ovino, por el contrario, busca las plantas más ricas intensificando su renuevo (Milne, 1987; Ibáñez Talegón, 2008; Espejo Díaz et al., 2008). En un pastizal pueden distinguirse varios estratos; en el superior dominan tallos de gramíneas y hojas viejas, un pasto con alto contenido en fibra, que es consumido por herbívoros grandes. En el estrato inferior, por el contrario, son frecuentes las hojas tier- 
nas del renuevo y dicotiledóneas herbáceas, ricas en proteínas, que son utilizadas por los herbívoros más pequeños, habitualmente más selectivos (Grobler, 1983; Aldezábal, 2001).

Cada especie muestra, además, preferencia por una topografía determinada, discriminando el uso del territorio. El vacuno busca pastos de talla alta $^{1}$, lo que unido a su fuerte dependencia de los puntos de abrevada, le lleva a pastar, sobre todo, áreas de suelo profundo y cierta fertilidad (fondos de valle, pies de vertiente, laderas cóncavas, rellanos, artesas glaciares, ibones colmatados,...). El ovino prefiere pastos cortos y finos, que obtiene en laderas de pendiente más o menos pronunciada. El cabrío es capaz de ascender a lo más alto de las cumbres y aprovechar las matas aisladas que en ellas sobreviven. El caballar, por su parte, necesita relieves suaves, no excesivamente accidentados, debido a la fragilidad de las patas, más de potros y yeguas que de mulas (Balcells, 1985). El equino prefiere los bordes de los pastizales, pastando si es posible en el límite con el matorral. Tiene una boca de gran potencia; los arbustos forman parte de su ración, si bien prefiere especies herbáceas. También tiende a situarse cerca de las superficies nevadas y asciende o desciende a medida que retrocede o avanza la nieve (Celada et al., 1989). García-González et al. (1990) estudiaron el movimiento del ganado en un puerto del Valle de Aísa (Pirineo Aragonés), con altitudes entre 1600 y 2600 m s.n.m. El ganado vacuno pastó generalmente en la parte baja, por debajo de los $1800 \mathrm{~m}$. Las ovejas pastaron entre 1800 y $2000 \mathrm{~m}$ en julio, primera quincena de agosto y septiembre, mientras que durante la segunda quincena de agosto ascendieron a la franja localizada entre 2200 y $2400 \mathrm{~m}$ de altitud. Los sarrios (Rupricapra p. pyrenaica) se mantuvieron a mayor altitud que los animales domésticos, si bien visitaban frecuentemente los lugares dispuestos para dar sal al ganado.

Se ha señalado también que el pastoreo combinado de varias especies produce el fenómeno conocido como facilitación (Montserrat, 1964; Gordon, 1988). La facilitación implica que la acción de unos herbívoros mejora las condiciones del pasto para que lo utilicen otras especies. El pastoreo de vacunos y équidos, eliminando las partes altas y fibrosas del pasto, permite a las ovejas aprovechar las partes más bajas; además, favorece la entrada de la luz, estimulando la generación y crecimiento de renuevos más ricos en proteínas (García-González, 2008 a).

${ }^{1}$ Osoro (1990) señala que la altura óptima a la que pastan las vacas es de $8 \mathrm{~cm}$. Por debajo no obtienen un nivel de ingestión adecuado, mientras que por encima se producen rechazos que disminuyen la calidad del pasto y aconsejan aumentar la intensidad del pastoreo. 
En los Andes Centrales, llamas y alpacas, aunque adaptadas ambas al pastoreo en alta montaña, tienen exigencias algo diferentes. Las alpacas, por lo general, buscan los pastos tiernos y siempre verdes de tierras inundadas (bofedales), donde pastan la mayor parte del año con pocos desplazamientos. Las llamas, por su parte, seleccionan poco, dada su alta capacidad para digerir vegetación con alto contenido de celulosa. En verano pastan en pisos altos, mientras que comparten los bofedales con las alpacas durante la estación seca (Molinillo y Monasterio, 1997a y 2006). Las vacas y ovejas, introducidas en la etapa de colonización española, tienden a concentrarse sólo en los mejores enclaves de los páramos, como consecuencia de su escasa adaptación al pastoreo en la vegetación dominante, de baja palatabilidad, compuesta por rosetas gigantes, gramíneas en macolla con gran cantidad de necromasa, cojines y arbustos (Molinillo y Monasterio, 2001).

Junto a la variedad de especies ganaderas la presencia de razas autóctonas garantiza el pleno aprovechamiento del territorio. Son animales adaptados a las condiciones ambientales de su territorio, capaces de caminar por relieves accidentados, de sobrevivir a los contrastes estacionales de disponibilidad y calidad del pasto sin sobrealimentación en establo, de aprovechar pastos bastos y, por supuesto, de necesitar escasa vigilancia del pastor. Por todo ello, se les considera como razas rústicas, con gran capacidad para consumir cualquier tipo de pasto y dotadas para transformar en carne recursos herbáceos muy baratos, a menudo gratuitos, que además sufren fuertes oscilaciones temporales (interanuales y estacionales). Se adaptan perfectamente al pastoreo y tienen un buen instinto gregario, notable economía del agua y facilidad para acumular y movilizar reservas adiposas, por lo que pierden y ganan peso rápidamente en función de la disponibilidad de alimentos sin que su salud ni la productividad se resientan. Son animales preparados para el multipropósito (trabajo-leche-carne; lana-leche-carne,...) con el fin de cubrir las múltiples necesidades de las poblaciones campesinas. Tienen facilidad para los partos, lo que hace más relajada la vigilancia del pastor, y alta capacidad maternal, lo que se manifiesta más en la alta tasa de supervivencia de las crías que en la prolificidad o precocidad. Son también características destacables de las razas autóctonas su longevidad y buena aptitud para el cruzamiento (García-Dory, 1980; Sierra, 1994 y 1996).

La diversidad de animales utilizados varía desde el reno en Finlandia, el yak y sus híbridos en el Himalaya, llamas y alpacas en los Andes, búfalos en la India y Nepal, camellos en áreas de Asia Occidental y norte de África, la multitud de variedades de ovinos, caprinos, vacunos y equinos en la mayor parte del mundo, y más recientemente ciervos en Escocia y Nueva Zelanda. La dis- 
tribución y utilidad de estos animales varía de acuerdo con las características ambientales y culturales de las regiones en que habitan.

Los animales son gestionados de forma colectiva, formando rebaños que obtienen sus recursos alimentarios en pastoreo. Por lo general, aprovechan recursos abundantes pero de regular o muy baja calidad, que sólo el ganado puede rentabilizar mediante su transformación en leche, carne, cuero, lana y pelos; productos que permiten la subsistencia de pueblos pastoriles, garantizando el autoconsumo e intercambios más o menos intensos. Algunos de tales ganados se utilizan también para la carga y el transporte: el yak en el Himalaya y la llama en los Andes fueron medios habituales para el comercio de granos y sal, recursos esenciales para la subsistencia (Flores Ochoa, 1988). La fuerza de tracción y la producción de estiércol han sido fundamentales en áreas con actividad agrícola (Feral, 1981; Osmaton, 1985). Por otro lado, y de manera menos común, la ganadería ha servido como signo de prestigio y para establecer arreglos matrimoniales en algunas culturas (Merlino y Rabey, 1983).

\section{RECURSOS PASCÍCOLAS Y ESTRATEGIAS DE PASTOREO}

Para superar el desequilibrio estacional de pastos se ha deforestado, aún se sigue haciendo, y abriendo claros en masas forestales de no pocas montañas de la Tierra (Mallet, 1978; Bencherifa, 1983; Metailié, 1984; O'Connor, 1984; Tucker, 1987; Mahat et al., 1987). Hay que recordar que el bosque tiene un reciclado lento, estabilizador, mientras que el pasto permite mantener una biomasa animal muy superior al acelerar los ciclos (Montserrat, 1972). Por otro lado, el desbroce de laderas de matorral y la puesta en cultivo de laderas marginales se hizo con fines agrícolas (Lasanta et al., 2006;), pero también ganaderos, ya que los rastrojos, barbechos y restos agrícolas se incorporaban al espacio pastoral en momentos claramente deficitarios en pastos (Puigdefábregas y Fillat, 1986). El fuego ha sido un elemento de gestión habitual en muchos ecosistemas de montaña. Quizás conviene destacar su uso para eliminar el cinturón superior del bosque con el fin de favorecer la expansión de pastos estivales, y de esta forma poder incrementar la cabaña ganadera y ampliar la estancia del ganado en los pastos supraforestales (Villar y García-Ruiz, 1977; Millones, 1982; Langenegger, 1984; Bertrand, 1984; Hrabovsky y Millan, 1987). Análisis palinológicos realizados en el Pirineo revelan que a partir del siglo XI se fue eliminando la parte superior del bosque, de tal manera que en la actualidad existe una banda de pastos subalpinos que corresponden al piso superior del bosque (Montserrat-Martí, 1992; García-Ruiz y Valero, 1998). En 
el mismo sentido, en el Sistema Ibérico riojano se ha constatado que desde el siglo xiII se deforestó para incrementar la superficie de pastos y alimentar a un censo ganadero muy elevado que trashumaba durante la estación fría a Extremadura y La Mancha (Calvo Palacios, 1977; Gil et al., 1996). Otras veces se han quemado matorrales para favorecer la salida de pasto más apetecible y de mayor calidad bromatológica. Williamson et al. (1986) señalan la utilización del fuego como una herramienta para mejorar la palatabilidad y accesibilidad al forraje en los pajonales de los páramos de Colombia. Genin et al. (1994) ponen de relieve el uso del fuego en algunos ambientes de puna andina para modificar la composición de la cubierta vegetal, dada la escasa eficiencia de la ganadería europea (vacas y ovejas) para consumir la vegetación dominante.

No obstante, conviene resaltar que en algunas áreas de montaña el bosque aclarado ha sido considerado como un recurso temporal de gran importancia (Galop, 1998). La asociación entre herbáceas y árboles resulta sumamente interesante porque ofrece una diversidad de recursos complementaria, en la medida en que la oferta está disponible en épocas distintas del ciclo anual y porque representa la posibilidad de una dieta más completa, al añadirse hojas y nuevos rebrotes (Montalvo et al., 1988). Por otro lado, árboles y arbustos proporcionan protección a las plantas de la radiación solar y a los animales de las inclemencias del tiempo (Narjisse, 1990). Asimismo, las raíces de los árboles bombean nutrientes desde las capas profundas del suelo hacia la superficie, mejorando la fertilidad y la oferta de pasto (González Bernáldez, 1995; De Miguel y Gómez-Sal, 2002; Montserrat, 2008). Por último, hay que tener en cuenta que algunos árboles (fresnos, robles, chopos,...) se consideran forrajeros, siendo sometidos a podas periódicas para dar las hojas al ganado en días climáticamente malos o durante la estación de mayor escasez de pastos. Gómez y Fillat (1981) señalan que en el Pirineo los fresnos se podaban para alimentar con sus hojas a las ovejas en invierno, y a los conejos con la corteza de la ramilla sobrante.

Aún con todo, en buena parte de las montañas la ganadería tuvo que buscar la alimentación fuera de su propio valle durante parte del año, mediante desplazamientos más o menos largos y duraderos. No se conoce suficientemente bien el origen de tales desplazamientos, aunque se admite de forma bastante generalizada que los rebaños de animales domésticos se empezaron desplazando a imagen y semejanza de las manadas salvajes (De Miguel, 1988; Gómez-Sal, 2004; Fillat, 2008). Lo cierto es que el pastoreo nómada y la trashumancia son desplazamientos que realizan tanto la ganadería como las manadas de herbívoros salvajes: ñúes de África, bisontes en Norteamérica, renos en Escandinavia, etc. (Ferrer y Broca, 1999). 
Existe toda una gama de desplazamientos que se diferencian por la longitud de los recorridos, la movilidad o no de la residencia familiar de los pastores y el origen territorial de los ganados. Simplificando mucho diremos que en las regiones de montaña han dominado tres tipos: nomadismo, trashumancia y combinación de agricultura y ganadería o agropastoreo. Todas constituyen adaptaciones culturales a cambios estacionales de los pastos. En el nomadismo, animales y familias de pastores se mueven entre los diferentes lugares de pastoreo sin tener una residencia permanente. La trashumancia implica el movimiento entre asentamientos permanentes, entre pastos de verano e invierno. En el agropastoreo sólo se mueven los animales dentro de un mismo valle o ladera de montaña, cerca de la zona de cultivos. Unas veces el ganado pasta sólo con visitas esporádicas del pastor, mientras que en otras ocasiones la vigilancia es más estricta, dirigiendo el pastor la marcha del rebaño. Molinillo y Monasterio (2002) señalan que en los páramos andinos no existen asentamientos permanentes de población, aprovechándose los pastos a partir de los asentamientos situados en el piso agrícola. En la estación de pastoreo en los páramos el ganado se deja con escaso control de los pastores, con sólo una o dos visitas al mes.

El pastoreo nómada se ha practicado en el Atlas y Altas Tierras del Este de África, en los Balcanes, Mediterráneo, Macizo Central afgano, Himalaya occidental y en las montañas de Asia Central: Pamir, Tien Shan y Altai (Broz, 2007). Se trata de un sistema que se adapta a los ritmos estacionales y complementarios de los pastos de bajas y altas tierras en regiones áridas y semiáridas. Familias y ganados recorren rutas más o menos establecidas, sin asentamientos permanentes, uniendo diferentes zonas de pastoreo. En la primavera y el verano aprovechan los pastos de montaña y en el invierno y otoño pastan en las tierras bajas. La distancia entre las zonas de pastoreo varían desde decenas de kilómetros, como en el Himalaya, hasta poco más de 1.000 km en Irán (Price, 1981). Las familias nómadas son, por lo general, étnica y culturalmente diferentes al resto de la población, con quienes comparten el territorio. Para subsistir intercambian los productos derivados de sus animales (carne, leche, cuero y lana) por los de sus vecinos. Debido a las características del pastoreo y del ambiente en el cuál se desarrolla, se dice que los nómadas ocupan un nicho ecológico que difícilmente podría ser utilizado de otra manera, incrementando así la productividad y diversidad en regiones áridas y semiáridas (Boyazoglu y Flamant, 1990). El nomadismo es una primitiva y eficaz manera de eludir la retroalimentación local negativa; mediante el desplazamiento de la población y de los animales, el hombre evita el agotamiento de los recursos locales y garantiza la subsistencia del grupo (Margalef, 1970). 
A diferencia de los nómadas, los pastores trashumantes tienen en los cultivos de tierra llana un medio de seguridad para disminuir el riesgo ante cualquier eventualidad, y un complemento forrajero para la dieta de los animales. Los desplazamientos entre los pastos de alta montaña y los invernales alcanzan, generalmente, distancias cortas (de pocas decenas de km), si bien suponen considerables diferencias de altitud. No obstante, en la cuenca mediterránea superan con frecuencia los $300 \mathrm{~km}$ (Ruiz y Ruiz, 1986). La trashumancia del ganado entre la montaña y las llanuras próximas se basa en la complementariedad entre producciones herbáceas que alcanzan su madurez en épocas distintas (Yasuda, 1958; Matley, 1968; Puigdefábregas y Balcells, 1970; Haggett, 1988, Rinschede, 1988; Rodríguez Pascual y Maya Frades, 2008). Pero la trashumancia no es sólo un sistema de gestión ganadera que permite superar baches estacionales en la producción de pastos, sino también un medio para disponer de capital líquido y capitalizar las áreas de montaña tras la venta de excedentes (lana, crías) y, por lo tanto, para incardinar a las áreas de montaña en el sistema económico general del país (Thorez y Réparaz, 1987). Por otro lado, se ha afirmado, refiriéndose a las montañas de Europa occidental, que trasladar la presión del ganado al exterior permitió dedicar la mayor parte del espacio agrícola a la alimentación del hombre, favoreciendo el pleno aprovechamiento del territorio, con altas densidades demográficas y elevados censos ganaderos (García Fernández, 1975; Lasanta, 1990).

Lo habitual en el mundo es que los rebaños trashumantes tengan su origen en tierra llana y se desplacen en la estación cálida (3-4 meses) a las montañas. Sin embargo, históricamente en España dominaron los traslados del ganado desde las montañas (Cantábrica, Pirineo y Sistema Ibérico, fundamentalmente) a los pastos de invernada, donde permanecían más de 7 meses, (Calvo Palacios, 1977; Ruiz y Ruiz, 1986; Pallaruelo, 1988; Gómez-Sal y Rodríguez-Pascual, 1992). Este tipo de trashumancia parece ilógica, ya que pastores y ganado estaban lejos más tiempo que en casa. De ahí, que Berezowski (1971) al clasificar los sistemas de movimiento del ganado denomina a la trashumancia española como inversa o descendente para diferenciarla de la imperante en el resto del mundo, a la que denomina directa o ascendente. Los desplazamientos desde las montañas del Norte de España hasta las dehesas del Sur y Sureste implicaban realizar largos recorridos, de hasta $800 \mathrm{~km}$ a veces. A este tipo de trashumancia algunos autores la denominan trashumancia latitudinal, para diferenciarla de otras más cortas (casi siempre con recorridos inferiores a los $100 \mathrm{~km}$ ) que se realizan entre una montaña y su piedemonte o entre montañas de diferentes altitudes (desde la vertiente norte de la Cantábrica hacia los llanos costeros; o desde el Sistema Ibérico Oriental hacia los 
llanos levantitos; o entre el Pirineo y Prepirineo, por ejemplo) a la que denominan trashumancia altitudinal (Pineda, 2004; Gómez-Sal, 2004).

El agropastoreo se practica en muchas montañas: Alpes, Pirineos, Caúcaso, Himalaya, Andes, Atlas, montañas de Nueva Zelanda y de Escandinavia. Por supuesto, la importancia de este sistema varía considerablemente entre las montañas, siendo muy destacado en montañas de latitudes medias, especialmente Alpes y Pirineos (Balent y Barrué-Pastor, 1986). En los Andes septentrionales los campesinos de los páramos complementan su agricultura de hortalizas y cereales con la ganadería vacuna. Los movimientos de los animales están estrechamente relacionados con el calendario agrícola y la disponibilidad de otros recursos forrajeros: restos de cultivos, céspedes naturales y barbechos (Hess, 1990; Molinillo y Monasterio, 1997). Molinillo y Monasterio (2002) ponen de manifiesto la alta dependencia, durante la estación seca, de la ganadería de los páramos de la Cordillera de Mérida (Andes venezolanos) de los restos agrícolas, mostrando que en tiempos recientes el desarrollo de una agricultura progresivamente más comercial implica una mayor utilización de los páramos y cambios en las estrategias de pastoreo, reemplazando las desarrolladas a nivel familiar a las comunitarias. En el Atlas, el agropastoreo se ha considerado como una buena estrategia para asegurar la alimentación del ganado y reducir los riesgos ambientales (Bencherifa, 1990).

\section{IMPACTO DEL PASTOREO SOBRE EL MEDIO}

El pastoreo implica necesariamente cambios en la vegetación, que se relacionan con el efecto de los animales (defoliación, extracción de biomasa, pisoteo, rozas y estercolado) (García-González, 2008), con las respuestas por parte de las plantas y de la comunidad vegetal (crecimiento compensatorio, cambios en las relaciones de competencias entre las plantas, variación en la composición florística, desarrollo de mecanismos de defensa,...) (McNaughton, 1986; Semmartin y Oesterheld, 1996) y con las actividades humanas vinculadas a él, como la deforestación y el desbroce. La intensidad y las características de tales cambios varían según la carga animal, los patrones de pastoreo y la capacidad de recuperación de la vegetación. Si la carga animal no es la adecuada (por exceso o por defecto) se produce la disminución de la productividad y, con el tiempo, cambios en la composición y estructura de la vegetación (Huntly, 1991; Montalvo et al., 1993; Milchumas et al., 1998).

El exceso de carga sobre un área da lugar al sobrepastoreo. Este implica la disminución o desaparición de la cubierta herbácea, con sus posibles efectos 
en la regulación hídrica, erosión del suelo, biodiversidad y estructura del paisaje (Morand-Fehr y de Simiane, 1977; Evans, 2005; Thornes, 2007). Además la disminución de la cubierta vegetal acarrea el empobrecimiento del banco de semillas por inhibición de la reproducción en las especies vegetales (Fuls, 1992). El sobrepastoreo no sólo disminuye la cubierta vegetal sino que también ejerce sus efectos sobre el suelo. Por un lado, el pisoteo del ganado apelmaza la tierra y compacta el suelo, modificando algunas de sus propiedades físicas (descenso de la porosidad, ruptura de agregados,...), lo que hace que disminuya la infiltración y aumente el flujo de escorrentía superficial y las pérdidas de suelo por erosión (Pérez y Díaz-Fierros, 1988; Fanning, 1994; Zhao et al., 2005). En un trabajo reciente, Blanco Sepúlveda (2008) incluye una relación de citas bibliográficas que muestran que la compactación del suelo por el ganado no es un proceso irreversible, sino que transcurrido un período más o menos largo se puede recuperar las propiedades físicas del suelo y más tarde la cubierta vegetal. Por otro lado, los animales con sus pezuñas levantan y movilizan el nivel superior de la capa edáfica; asimismo, en suelos desnudos y con bajo contenido de humedad pulverizan parte de la corteza superficial, originando en ambos casos un material suelto fácilmente transportable por los flujos superficiales. En este sentido, Serrate (1977) comprobó en una pequeña parcela experimental de $5 \mathrm{~m}^{2}$, localizada en una ladera de los Alpes franceses, que el paso de un rebaño suponía el desplazamiento de $1 / 2 \mathrm{~m}^{2}$ de suelo. Los pasos frecuentes del ganado son áreas proclives a la concentración de flujos de escorrentía y al inicio de procesos de erosión. Así en el Sistema Ibérico riojano se ha constatado que algunos desprendimientos en el muro externo del bancal tienen su origen en los desplazamientos del vacuno (Lasanta et al., 2001). También las altas concentraciones temporales del ganado originan pérdidas de suelo por erosión, como ha observado Molinillo (1993) en los Andes argentinos.

Con el fin de equilibrar pastos y carga ganadera se ha recurrido con frecuencia al uso del fuego para eliminar matorrales y favorecer la salida del pasto (Lenclud y Pernet, 1978; Lasanta y Ortigosa, 1992; Herrera, 1995; Hofstede et al., 1995); en algunos casos también a la deforestación (MontserratMartí, 1992; Gil et al., 1996; García-Ruiz y Valero, 1998). Actividades todas ellas estrechamente relacionadas con la degradación de la vegetación y la erosión del suelo (Naveh y Whittaker, 1979; García-Ruiz y Del Barrio, 1990).

En montañas de regiones semiáridas, caracterizadas por baja oferta de pastos y baja capacidad de recuperación de la vegetación, son habituales las prácticas de quema con el fin de disminuir las leñosas y aumentar la proporción de especies más palatables. En regiones más húmedas, el fuego, utilizado en las 
partes altas, ha servido para transformar los pastizales en una vegetación más basta, dominada por céspedes o cojines (Nueva Zelanda), arbustos bajos y herbáceas asociadas (Australia) o en céspedes (regiones andinas). En definitiva, el sobrepastoreo, acompañado por deforestación, desbroce de matorrales y el uso del fuego, suele conducir a la disminución de la cubierta vegetal y a la instalación de procesos erosivos, más o menos agresivos, que determinan la disminución de la calidad de los suelos y de los pastos.

Cuando el pastoreo es muy leve o moderado o cuando queda totalmente excluido, como a veces ocurre en algunas reservas naturales, se habla de infrapastoreo. En estos casos, el territorio tiende a ser invadido por arbustos, se hace impenetrable, pierde riqueza específica y biodiversidad, aumenta la probabilidad, periodicidad e intensidad de los incendios, y con ello se disparan las tasas de erosión; la estructura del paisaje se hace más homogénea, y la disponibilidad de agua en las cuencas disminuye, especialmente en medios mediterráneos y semiáridos (Naveh y Kutiel, 1990; Le Houèrou, 1993; Vicente-Serrano et al., 2000; Beguería et al., 2003; Vos y Meekes, 1997; Laiolo et al., 2004). Perevolotsky y Seligman (1998) señalan que el infrapastoreo conduce a lo que ellos denominan «desierto verde», un problema mucho más grave que el sobrepastoreo, según Ferrer y Broca (1999).

Una carga ganadera equilibrada con los pastos implica el incremento de la diversidad vegetal y la formación de una estructura paisajística más compleja y heterogénea. Así, se admite que tanto el pastoreo moderado como el intenso constituyen perturbaciones intermedias que contribuyen a incrementar la riqueza específica de la cubierta vegetal y la biodiversidad. El pastoreo actúa sobre la riqueza específica mediante la selección que el ganado hace en el consumo de hierbas, lo que modifica las relaciones de competencia y cooperación entre plantas (Canals y Sebastià, 2000). El pisoteo, por su parte, crea huecos de suelo desnudo, que cumplen el papel de microhábitats, los cuáles se comportan como nichos de regeneración de una vegetación distinta a la de las áreas próximas, bien por llegada de semillas siguiendo modelos al azar (Bullock et al., 1994), o por verse favorecidas aquellas que, estando presentes en el banco de semillas, necesitan luz y espacio para progresar (Hulme, 1996). Por otro lado, la presencia de ganado contribuye a fragmentar el paisaje y a crear estructuras más complejas, con teselas más pequeñas y una configuración de usos y cubiertas del suelo más compleja (Lasanta et al., 2005). Gómez (2008) señala que los ecosistemas pastorales reúnen una abundante riqueza de especies, comunidades y paisajes de las montañas. Así, de los 128 grandes tipos de paisajes reconocibles en el Noroeste de la Península Ibérica, 31 han sido originados y mantenidos por la ganadería. Para la misma región se consi- 
dera que de las 266 comunidades vegetales definidas como hábitats prioritarios en la Directiva Hábitats de la UE, 108 son comunidades pascícolas. Además, alrededor de 1000 especies (más del 40\% del total de la flora del Pirineo) se encuentran entre los pastos, y el 53\% de los endemismos vegetales del Pirineo forman parte de los pastos.

\section{LOS CAMBIOS RECIENTES EN EL PASTOREO DE MONTAÑA}

El pastoreo de montaña está cambiando de forma más o menos rápida en función de las fuertes presiones (económicas, sociales, ecológicas) que llegan del exterior. La intensificación de la actividad agrícola en las llanuras próximas, la llegada masiva de turistas a las montañas, el desarrollo de planes agrícolas sobre áreas tradicionalmente ganaderas, la creación de reservas y parques naturales, los planes de reforestación en laderas marginales, la industrialización de algunos valles, la dedicación de cuencas enteras exclusivamente para la regularización hídrica y producción de agua, constituyen cambios recientes con consecuencias sobre la ganadería. Se trata, por lo general, de la disminución de tierras, del establecimiento de fuertes limitaciones para la ganadería o de la creación de nuevas alternativas económicas y laborales (Hess, 1990; García-Ruiz y Lasanta, 1993).

El pastoreo nómada, como forma de vida y actividad económica, se mantiene muy vivo en los altiplanos de Mongolia y Rusia, pero encuentra fuertes dificultades para mantenerse en muchas otras montañas. El incremento de la presión poblacional, la expansión de la agricultura, los avances tecnológicos, las restricciones políticas, los conflictos intertribiales o intergrupales por el control de las aguas de abrevada y los pastos, la puesta en marcha de teorías de desarrollo endógeno traídas desde los países desarrollados son algunas de las causas que dificultan el desplazamiento de los rebaños de un lugar a otro y que perjudican notablemente la pervivencia del nomadismo ganadero (Antón Burgos, 2000). En el sudoeste asiático los nómadas disponen cada vez de menos tierras, debido a los avances de la agricultura y a las dificultades para unir zonas de pastoreo (Khazanov, 1998). En el Atlas, la ganadería nómada se ha sedentarizado durante las últimas décadas, presionando más sobre los pastos de las áreas llanas (Bencherifa y Johnson, 1991), a la vez que se asiste a cierta desorganización en el pastoreo de pastos comunales; la sedentarización de la población conduce a conflictos sobre la propiedad y derecho de los pastos colectivos más próximos a los núcleos de población y al abandono de otros menos accesibles (Boumaza, 1996). En este sentido, en el Sur de Túnez 
se estima que los pastos soportan en la actualidad una carga ganadera de 0,25 a 0,70 ovejas/ha/año, mientras que la capacidad de carga estimada es de 0,15 a 0,20 ovejas/ha/año (Hanafi y Jauffret, 2008). El abandono de pastos naturales implica que con cierta frecuencia haya que acudir a la compra en el exterior de piensos concentrados (Puigdefábregas y Mendizábal, 1998).

La trashumancia tropieza con dificultades muy variadas, que van desde la intensificación del uso de la tierra en las áreas llanas (urbanización, industrialización, densificación de las vías de comunicación, puesta en regadío de extensas superficies, roturación de eriales,...), con la consiguiente disminución y encarecimiento de los pastos, a la crisis del oficio de pastor, pasando por la pérdida de muchas rutas (cañadas, cordeles y veredas) utilizadas tradicionalmente por los rebaños. Los grandes desplazamientos trashumantes pasan por una profunda crisis desde mediados del siglo xx, si bien un siglo antes se atisbaron signos evidentes de decadencia (Ruiz, 2004). En los Alpes, Pirineos, Cantábrica, se mantienen el ascenso estival a los pastos supraforestales desde los pueblos próximos, en un sistema que cabe denominar más como trasterminante o trastermitante que trashumante (Pallaruelo, 1993). No obstante, cabe señalar que las ayudas de la Política Agraria Comunitaria (PAC) a la ganadería extensiva han favorecido cierta recuperación de la trashumancia, al menos en el gradiente Pirineos-Valle del Ebro (Lasanta y Errea, 2008). En el mismo sentido, han contribuido a mantener los censos y a incrementar el tamaño de las explotaciones, más en los municipios con escasa actividad turística que en aquellos que encuentran en los deportes de invierno una alternativa económica (Laguna y Lasanta, 2007).

La PAC ha favorecido el regreso de los rebaños a algunas áreas de montaña, con un enfoque más conservacionista que productivista (Green, 1990; Dutoit et al., 1995). Sin embargo, algunos autores (Caballero et al., 1992; Ferrer y Broca, 1999) señalan que es difícil que los ganaderos mantengan sus explotaciones sin incentivos económicos. Para estos autores no se puede pedir al ganadero que actúe como policía ecológico o como guardián de la naturaleza, tal como apunta en cierta medida la PAC desde la reforma de 1992, sino que es necesaria la adopción de medidas económicas (que hagan rentables las explotaciones), sociales (mejora en las condiciones de trabajo) y ecológicas (que los beneficios medioambientales se hagan visibles, cuantificables y demostrables).

En el Himalaya, nomadismo y trashumancia decaen progresivamente, tanto por la expansión de la agricultura de subsistencia, que extrae campos dedicados anteriormente a la producción de forrajes, como por el aumento de la cabaña ganadera vinculada al turismo, lo que incrementa la competencia por los pastos (Dangwal, 1999; Duncan et al., 2006; Shaoliang et al., 2007). 
También el pastoralism tradicional de los Andes experimenta profundos cambios por la irrupción brusca de la economía de mercado durante las últimas décadas, lo que ha alterado la organización social, económica y cultural de las sociedades campesinas. La ganadería ha dejado de ser en no pocas regiones andinas un mero complemento económico para convertirse en el principal motor de la economía, lo que lleva a una creciente presión sobre los mejores pastos y a la marginación de los más bastos (Hess, 1990; White y Maldonado, 1991). Por otro lado, la expansión del vacuno y ovino ha tenido fuertes consecuencias sobre el ambiente y sobre la ganadería autóctona. Tanto en los páramos como en las punas de Colombia y Ecuador se recurre frecuentemente al fuego para mejorar la palatabilidad y accesibilidad a los pastos, con degradación de la vegetación natural (Genin et al., 1994; Williamson et al., 1986). En los paramos argentinos y venezolanos la evolución ganadera tiende a la concentración de los rebaños en las áreas más accesibles desde los pueblos, con amenaza de sobrepastoreo y de pérdida de cubierta vegetal e incremento de las tasas de erosión, mucho más si se tiene en cuenta que el apoyo forrajero obtenido del espacio cultivado desciende progresivamente por la expansión de cultivos especulativos en detrimento de los forrajeros (Molinillo, 1993; Molinillo y Monasterio, 2002). En los Andes peruanos, la ganadería de alpacas se orienta cada vez más hacia el mercado, sobre todo europeo, lo que está modificando el sistema de pastoreo tradicional: se expanden los prados de siega en detrimento de otros cultivos, a la vez que la productividad de los mejores pastos naturales se potencia con apoyo del riego, se incrementan las rotaciones entre los pastos más apetecibles y se abandonan los peores y más alejados (Postigo et al., 2008). La mayor presión sobre los mejores recursos pastorales lleva a una creciente privatización de la tierra y del agua, mientras que el espacio comunal pierde interés ganadero (Lesorogol, 2003).

Las razas autóctonas han sido sustituidas o lo están siendo por otras más selectas, con mayores rendimientos en canal y más exigentes en el consumo de pastos. Así, por ejemplo, en las montañas españolas el vacuno autóctono ha sido progresivamente sustituido por razas importadas, buscando mayores rendimientos de carne, una vez que perdió interés mantener razas con triple aptitud (carne, leche, trabajo) (Balcells, 1985). La sustitución de razas implica, en primer lugar, que algunas de las autóctonas hayan desaparecido, otras se encuentren amenazadas de desaparición, y otras no han sido mejoradas ni adaptadas, perdiendo la competitividad que tuvieron en el pasado; la desaparición de ganado autóctono supone la pérdida de un material genético perfectamente adaptado, por selección natural, al aprovechamiento sostenido 
de los recursos pascícolas de su área (García-Dory y Martínez, 1988; Sierra, 1996). En segundo lugar, supone que una proporción de pastos dejan de consumirse, ya que, por un lado, las razas autóctonas seleccionan más las especies a consumir, y, por otro lado, discriminan en el uso del territorio, marginando las laderas muy pendientes y alejadas de los establos. García-Ruiz y Lasanta (1993) han comprobado en el Pirineo que existe una relación directa entre censos ganaderos y producción de forraje, lo que supone que una proporción elevado de los pastos naturales dejan de aprovecharse; la alimentación del ganado depende casi exclusivamente de los prados cultivados y de los pastos supraforestales, mientras que las laderas intermedias (cubiertas por antiguos campos de cultivo, matorrales y bosques) apenas aportan nada. En Cameros Viejo (Sistema Ibérico) el ganado (básicamente vacuno de razas Pardo-alpina, Charolais y Hereford) se concentra en los alrededores de los establos, cerca de los puntos de abrevada y de distribución de pienso, olvidándose del pastoreo en la mayor parte del territorio. La escasez de prado, por limitaciones ambientales, obliga a los ganaderos a comprar piensos en el exterior (casi el 50\% del consumo total) para completar la alimentación de sus rebaños (Lasanta, 2009).

La disminución de los censos ganaderos y la sustitución de razas han obligado a modificar los itinerarios de pastoreo, concentrándose el ganado recientemente en los enclaves con pasto más apetecible, mientras que muchas laderas apenas son visitadas por el ganado. Ello implica la degradación progresiva de los pastos y el desarrollo de procesos de revegetación, con presencia progresivamente creciente de matorrales y bosques de sucesión, que homogeneizan el paisaje (Lasanta et al., 2005; Chauchard et al., 2007).

En general, los fuertes cambios económicos y sociales, registrados durante las últimas décadas en la mayor parte de las montañas, implican degradaciones ambientales severas, con especial incidencia en las montañas tropicales y subtropicales. Muchas de las sociedades que mantenían prácticas ecológicas adaptadas al aprovechamiento sostenido de los recursos las han abandonado a favor de enfoques más economicistas y frecuentemente menos conservacionistas. El futuro del pastoralism de montaña está comprometido, y con ello también el futuro de muchas culturas tradicionales, que habían llegado a un compromiso entre estabilidad ambiental y productividad utilizable.

Agradecimientos: Este trabajo se ha realizado en el marco de los proyectos de investigación: PROBASE, «Procesos y balances de sedimentos a diferentes escalas espaciales en ambientes mediterráneos: Efectos de las fluctuaciones climáticas y de los cambios de uso del suelo» (CGL2006-11619/HID), y «Análisis de escenarios de riesgo a escala nacional y global» (CGL2008-01083/CLI), am- 
bos financiados por el Plan Nacional de I+D. También ha contado con la ayuda del «Programa de grupos de investigación consolidados», financiado por el Gobierno de Aragón.

Recibido: 28/04/2009

Aceptado: 26/03/2010

\section{Bibliografía}

Aldezabal, A. (2001): El sistema de pastoreo del Parque Nacional de Ordesa y Monte Perdido (Pirineo Central, Aragón). Interacción entre la vegetación supraforestal y los grandes herbivoros. Consejo de Protección de la Naturaleza de Aragón, 28: 317 pp., Zaragoza.

Antón Burgos, F. J. (2000): Nomadismo ganadero y trashumancia: balance de una cultura basada en su compatibilidad con el medio ambiente. Anales de Geografía de la Universidad Complutense, 20: 23-31.

Balcells, E. (1985): Reciente transformación de la cabaña ganadera. III Coloquio Nacional de Geografía Agraria. Asociación de Geógrafos Españoles, 163-237, Cáceres.

Balent, G. y Barrué-Pastor, M. (1986): Pratiques pastorales et strategies foncières dans le processus de déprise de l'élevage montagnard en vallée d'Oô (Pyrénées centrales). Revue Géographique des Pyrénées et du Sud-Ouest, 57 (3): 403-447.

Barry, R. G. e Ives, J. D. (1974): Introduction. In: Artic and Alpine Environments (Barry, R. G. e Ives, J. D., eds.). Methuen: 1-13, London.

Beguería, S., López-Moreno, J. I., Lorente, A., Seeger, M. y García-Ruiz, J. M. (2003): Assessing the effects of climate oscillations and land-use changes on streamflow in the Central Spanish Pyrenees. Ambio, 32 (4): 283-286.

Bencherifa, A. (1983): Land use and equilibrium of mountain ecosystems in the hight Atlas of western Morocco. Mountain Research and Development, 3 (3): 273-279.

Bencherifa, A. (1990): Demography and cultural ecology of the Atlas Mountains of Morocco: Some new hypothesis. In: African mountains and highlands: problems and perspectives (B. Messerli and H. Hurni, eds.). African Mountains Association: 369-377.

Bencherifa, A. y Johnson, D. L. (1991): Changing resource management strategies and their environmental impacts in the Middle Atlas Mountains of Morocco. Mountain Research and Development, 11 (3): 183-194.

Berezowski, S. (1971): Typologie des migrations pastorales en Europe et méthodes de leurs études. L'aménagement de la montagne, 87: 165-174.

Bertrand, G. (1984): Apogée et déclin d'une géosystème silvo-pastoral (montagne de León et de Palencia, Espagne du nord-ouest). Revue Géographique des Pyrénées et du Sud Ouest, 55 (1): 239-248. 
Blanco Sepúlveda, R. (2008): La evaluación de la vulnerabilidad del suelo a la degradación por uso ganadero en espacios montañosos. Análisis metodológico. Estudios Geográficos, 264: 51-80.

Boumaza, N. (1996): Crise, action et mutations: le Haut.-Atlas marocain et les effects d'une programmation du tourisme. Revue de Géographie Alpine, 84 (4): 25-50.

Boyazoglu, J. y Flamat, J. C. (1990): Mediterranean systems of animal production. In: The world of Pastoralism (J. C. Galaty and D. R. Johnson, eds.). The Guelfordd Press: 353-393, New York.

Broz, L. (2007): Pastoral perspectivism: A view from Altai. Inner Asia, 9 (2): 291-310.

Browman, D. L. (1974): Pastoral nomadism in the Andes. Current Antropology, 15: 2188-2196.

Bullock, J. M., Clear Hill, B., Dale, M. P. y Silvertown, J. (1994): An experimental study of the effects of sheep grazing on vegetation change in an species-poor grassland on the role of seedling recruitment in gaps. Journal of Applied Ecology, 31: 493-507.

Caballero, R., Arauzo, M., García, C. y Meco, R. (1992): La integración ovina en los sistemas agrícolas de Castilla-La Mancha. Una alternativa a la agricultura convencional. Instituto de Alimentación Animal de Madrid (CSIC). Servicio de Investigación y Experimentación Agraria (Junta de Castilla-La Mancha), 34 pp., Madrid.

Calvo Palacios, J. L. (1977): Los Cameros. De región homogénea a espacio-plan. Instituto de Estudios Riojanos, 2 vols, Logroño.

Canals, R. M. y Sebastià, M. T. (2000): Analyzing mechanisms regulating diversity in rangelands through comparative studies: a case in the southwestern Pyrenees. Biodiversity and Conservation, 9: 965-984.

Celada, J. D., Zorita, E. y Gaudioso, V. R. (1989): La degradación de los pastos naturales españoles y su relación con la crisis de la ganadería extensiva. Papel de la cabra en el mantenimiento y recuperación de los ecosistemas pastorales. Avances en alimentación y mejora animal, 29 (2): 64-71.

Chauchard, S., Carcaillet, C. y Guidal, F. (2007): Patterns of land use abandonment control tree-recruitment and forest dynamics in Mediterranean mountain. Ecosystems, 10: 936-948.

Chocarro, C. y Reiné, R. (2008): El cultivo de los prados en el Pirineo. En Pastos del Pirineo (F. Fillat, R. García-González, D. Gómez y R. Reiné, eds.). CSIC y Diputación de Huesca, 151-158, Huesca.

Dangwal, P. (1999): La crisis del pastoralismo nómada en el Himalaya Central en India. Rural litigation and entitlement. Forum Internacional sobre Nomadismo y Trashumancia. Watu-Ministerio de Medio Ambiente, 10 pp., Madrid.

De Miguel, E. (1988): La trashumancia: importancia económica y modelo de aprovechamiento. Actas de la XXXVIII Reunión de la S.E.E.P., 337-342.

De Miguel, J. M. y Gómez-Sal, A. (2002): Diversidad y funcionalidad de los paisajes agrarios tradicionales en España. En: La diversidad biológica en España (F. D. Pineda, J. M. de Miguel, M. A. Casado y J. Montalvo, eds.). CYTEd-Prentice may, 273-284. 
De Vries, D., Leslie, P. W. y Mccabe, J. T. (2006): Livestock acquisitions dynamics in Nomandic pastoralist herd demography: A case study among Ngisonyoha Herders of South Turkana, Kenya. Human Ecology, 34: 11-25.

Duncan, A. J., Rahman, A., Miller, D. W., Frutos, P., Gordon, I. J., Rehman, A. Baig, A. A. F y Wrigth, I. A. (2006): Transhumance livestock production in the Northern Areas of Pakistan: Nutritional inputs and productive outputs. Agriculture, Ecosystems and Environment, 117 (2/3): 195-204.

Dutoit, T., Alard, D., Lambert, J. y Frileux, P. N. (1995): Biodiversité et valeur agronomique des pelouses calcicoles: effects du pâturages ovin. Fourrages, 142: 145-158.

Espejo Díaz, M., López Gallego, F. y Espejo Gutiérrez De Tena, A. M. (2008): Pastoreo en la especie ovina. En: Ovinotecnia. Producción y Economía en la especie ovina. Prensas Universitarias de Zaragoza, 167-189, Zaragoza.

Evans, R. (2005): Curtailing grazing-induced erosion in a small catchment and its environs, the Peak District, Central England. Applied Geography, 25: 81-95.

FAO (2001): Pastoralism in the new millennium. Animal production and health, 150. FAO, Roma.

Fanning, P. (1994): Long-term contemporary erosion rates in an arid rangelands environment in western New South Wales, Australia. Journal of Arid Environments, 28: 173-187.

Feral, P. L. (1981): Lapplication des lois de 1860, 1864 et 1882 sur le reboisement et le gazonnement des Montagnes. Les frutières du Haut-Cominges. Revue de Comminges, 94 (1): 108-124.

Ferrer, C. (1988): Los recursos pascícolas en el Pirineo Aragonés. XXXVIII Reunión de la S.E.E.P., 23-65, Jaca.

Ferrer, C. y Broca, A. (1999): El binomio agricultura-ganadería en los ecosistemas mediterráneos. Pastoreo frente a "desierto verde". Actas de la XXXIX Reunión de la S.E.E.P., 309-334, Almería.

Ferrer, C., San Miguel, A. y Olea, L. (2001): Nomenclátor básico de pastos en España. Pastos, 31: 7-44.

Fillat, F. (2008): Bosquejo histórico de la actividad pastoril en el Pirineo. En: Pastos del Pirineo (F. Fillat, R. García-González, D. Gómez y R. Reiné, eds.). CSIC y Diputación de Huesca, 25-35, Huesca.

Flamant, J. C. y Cocks, Ph. (1989): Adaptation des systèmes d'élevage aux resources fourragères en zone méditerranéenne. XVI Congrès International des Herbages, 1741-1752, Niza, Francia.

Flores Ochoa, J. (1988): Lamichos y Pagocheros, pastores de llamas y alpacas. Centro de estudios andinos. Cuzco.

Fuls, E. R. (1992): Ecosystems modification created by patch-over-grazing in semiarid grasslands. Jounnal of Arid Environment, 23: 59-69.

Galop, D. (1998): La forêt, l'homme et le troupeau dans les Pyrénées. 6000 ans d'histoire de l'environment entre Garonne et Méditerranée - GEODE. Laboratoire d'Ecologie Terrestre - Franespa, 285 pp., Toulouse. 
García-Dory, M. A. (1980): La utilización de las razas autóctonas en los ecosistemas regionales, como factor de ahorro energético en la ganadería española. Agricultura y Sociedad, 15: 115-162.

García-Dory, M. A. y Martínez, S. (1988): La ganadería española ¿desarrollo integrado o dependencia? Alianza Editorial, Madrid.

Garcia Fernandez, J. (1975): Organización del espacio y economía rural en la España Atlántica. Siglo xxi, 331 pp., Madrid.

García-González, R. (2008): Los pastos y su relación con los herbívoros: aspectos fundamentales de la interacción pasto-herbívoro. En: Pastos del Pirineo (F. Fillat, R. García-González, D. Gómez y R. Reiné, eds.). CSIC y Diputación de Huesca, 9-15, Huesca.

García-González, R. (2008a): La utilización de los pastos por los grandes herbívoros: principios básicos y casos de estudio. En: Pastos del Pirineo (F. Fillat, R. GarcíaGonzález, D. Gómez y R. Rainé, Eds). CSIC y Diputación de Huesca, 205-227, Huesca.

García-González, R., Hidalgo, R. y Montserrat, C. (1990): Patterns of livestock use in time and space in the summer ranges of the Western Pyrenees. A case study in the Aragon Valley. Mountain Research and Development, 10 (3): 241-255.

García-Ruiz, J. M. (1990): La montaña: una perspectiva geoecológica. En: Geoecología de las áreas de montaña (J. M. García-Ruiz, ed.). Geoforma Ediciones, 15-31, Logroño.

García-Ruiz, J. M. y Del Barrio, G. (1990): Effects géomorphologiques des activités humaines dans les milieux supraforestiers des Pyrénées espagnoles. Revue Géographique des Pyrénées et du Sud-Ouest, 61 (2): 255-270.

García-Ruiz, J. M. y Lasanta, T. (1989): La ganadería extensiva en áreas de montaña marginales: algunos problemas teóricos y prácticos. Anales del Instituto de Estudios Agropecuarios, 11: 77-94.

García-Ruiz, J. M. y Lasanta, T. (1993): Land-use conflicts as a result of land-use change in the Central Spanish Pyrenees. Mountain Research and Development, 13 (3): 295-304.

García-Ruiz, J. M. y Valero, B. (1998): Historical geomorphic processes and human activities in the Central Spanish Pyrenees. Mountain Research and Development, 18: 309-320.

Genin, D., Villca, Z. y Abasto, P. (1994): Diet selection and utilization by llama and sheep in high altitude arid rangeland of Bolivia. Journal of Range Management, 47: 245-248.

Gibon, A. (2005): Managing grassland for production, the environment and the landscape. Challenges at the farm and the landscape level. Livestock Production Science, 96: 11-31.

Gil, M. J., Tomás, R., Núñez, E. y Martínez-Abaigar, J. (1996): Acción humana sobre el medio natural en la sierra de Cameros a partir de análisis polínicos. Zubía, monográfico, 8: 29-41. 
Gómez, D. (2008): Métodos para el estudio de los pastos, su caracterización y valoración. En: Pastos del Pirineo (F. Fillat, R. García-González, D. Gómez y R. Reiné, eds.). CSIC y Diputación de Huesca,75-109, Huesca.

Gómez, D. y Fillat, F. (1981): La cultura ganadera del fresno. Pastos, 11: 295-302.

Gómez-Sal, A. (2001): The ecological rationales and nature conservation value of extensive livestock systems in the Iberian Peninsula. In: Examples of European agrienvironmental schemes and livestock systems and influence on Spanish cultural landscapes (Bunce, R. G. H., ed.). Alterra-rapport, 309: 103-123, Wageningen.

Gómez-Sal, A. (2004): Fundamentos ecológicos y la importancia del medio natural en los sistemas de ganadería extensiva en la Península Ibérica. En: Medidas agroambientales y sistemas ganaderos en Europa. Su contribución a la conservación de los paisajes culturales. Consejería de Agricultura y Pesca. Junta de Andalucía, 119141, Sevilla.

Gómez-Sal, A. y Rodríguez-Pascual, M. (1992). Cuadernos de la Trashumancia, 3: Montaña de León. ICONA, Madrid.

González-Bernáldez, F. (1995): Western Mediterranean land use systems as antecedents for semiarid America. In: Global Land Use Change. A perspective from the Columbian Encounter (B. L. Turner, A. Gómez-Sal, F. González-Bernáldez y F. di Castri, eds.). CSIC, 131-151, Madrid.

Gordon, I. J. (1988): Facilitation of reed deer grazing by cattle and its impact on red deer perfomance. Journal of Applied Ecology, 25: 1-10.

Granda, M. y Prieto, P. M. (1986): El merino como factor de aprovechamiento de recursos alimenticios en medios difíciles. Trashumancia. Congreso Mundial del Merino, 149-163, Madrid.

Green, B. H. (1990): Agricultural intensification and loss of habitat, species and amenity in British grasslands: a review of historical change and assessment of future prospects. Grass and Forage Science, 45: 365-372.

Grobler, J. H. (1983): Feeding habitats on the Cape Mountain Zebra. Equus zebra zebra Linn. 1758. Koedoe, 26: 159-168.

Haggett, P. (1988): Geografía, una sintesis moderna. Ediciones Omega, S.A., Barcelona.

Hall, K., Boelhommers, J. y Driscoll, K. (1999): Animals as erosion agents in the alpine zone: Some data and observations from Canada, Lesotho, and Tibet. Arctic, Antarctic and Alpine Research, 31 (4): 436-446.

Hanafi, A. y Jauffret, S. (2008): Are long-term vegetation dynamics useful in monitoring and assessing desertification processes in the arid steppe, southern Tunisia. Journal of Arid Environments, 72 (4): 557-572.

Herrera, P. M. (1995): Ganadería e incendios forestales. Quercus, 107: 35-37.

Hess, G. (1990): "Movinp up-moving down": agropastoral land use patterns in Ecuadorian Paramos. Mountain Research and Development, 10: 333-342.

Hofstede, R., Mondragón, M. X. y Rocha, C. M. (1995): Biomass of grazed, burned, and undisturbeb Paramo grasslands, Colombia. I. Above ground vegetation. Artic and Alpine Research, 27: 13-18. 
Hrabovsky, J. P. y Miyan, K. (1987): Population gowth and land use in Nepal "the great turnabout". Mountain Research and Development, 2 (2): 141-156.

Hulme, P.E. (1996): Herbivory, plant regeneration and species coexistence. Journal of Ecology, 84: 609-615.

Huntly, N. (1991): Herbivores and the dynamics of communities and ecosystems. Annual Revue Ecological Systems, 22: 477-503.

Ibáñez Talegón, M. (2008): Comportamiento de ovejas y cabras. En: Ovinotecnia. Producción y Economía en la especie ovina. Prensas Universitarias de Zaragoza: 49-56, Zaragoza.

Khazanov, A. (1998): Pastoralists in the contemporary world: the problem of survival. In: Changing Nomads in a Changing World (J. Ginat and A. Khazanov, eds.). Sussex Academic: 7-23, Sussex.

Laguna, M. y Lasanta, T. (2007): Balance de las políticas públicas en el desarrollo rural del Pirineo Aragonés. Boletín de la Asociación de Geógrafos Españoles, 43: 29-49.

Laiolo, P., Dondero, F., Ciliento, E. y Rolando, A. (2004): Consequences of pastoral abandonment for the structure and diversity of the alpine avifauna. Journal of Applied Ecology, 41: 294-304.

Langenegger, H. (1984): Mountain forests: dynamics and stability. In: The transformation of Swiss mountain regions (Brugger, E., Furrer, G., Messerli, B. \& Messerli, P., eds.), 361-372, Berna.

Lasanta, T. (1989): Evolución reciente de la agricultura de montaña: El Pirineo Aragonés. Geoforma Ediciones, 220 pp., Logroño.

Lasanta, T. (1990): Tendances actuelles de l'organisation spatiale des montagnes espagnoles. Annales de Géographie, 551: 51-71.

Lasanta, T. (2002): Los sistemas de gestión en el Pirineo español durante el siglo Xx. Ager, 2: 173-195.

Lasanta, T. (2009): La ganadería de Cameros: entre la adaptación a los recursos y la dependencia del exterior. En: Gestión, usos del suelo y paisaje en Cameros (Sistema Ibérico, La Rioja) (T. Lasanta y J. Arnáez, eds.). Universidad de La Rioja - Instituto de Estudios Riojanos, 191-222, Logroño.

Lasanta, T., Arnáez, J., Oserín, M. y Ortigosa, L. (2001): Marginal lands and erosion in terraced fields in the Mediterranean mountains. A case study in the Camero Viejo (Northwestern Iberian System, Spain). Mountain Resarch and Development, 21 (1): 69-76.

Lasanta, T., Beguería, S. y García-Ruiz, J. M. (2006): Geomorhic and hidrological effects of tradicional shiffting agricultura in a Mediterranean mountain area, Central Spanish Pyrenees. Mountain Research and Development, 26 (2): 146-152.

Lasanta, T. y Errea, M. P. (1997): Cambios recientes entre agricultura y ganadería extensiva: de la complementariedad a la dependencia de la ganadería. Polígonos, 7: 47-75.

Lasanta, T. y Errea, M. P. (2008): Revitalización de la trashumancia por la PAC en el gradiente Pirineos - Depresión del Ebro. En: Los espacios rurales españoles en el nuevo siglo (J. M. Gómez Espín y R. Martínez Medina, eds.), 35-47, Murcia. 
Lasanta, T. y Ortigosa, L (1992). Estrategias recientes en el aprovechamiento de áreas montañosas marginales: repercusiones económicas y ecológicas en Camero Viejo (Sistema Ibérico). Ería, 27: 21-31.

Lasanta, T., Vicente-Serrano, S. y Cuadrat, J. M. (2005): Mountain mediterranean landscape evolution caused by the abandonment of traditional primary activities: a study of tje Spanish Central Pyrenees. Applied Geography, 25: 47-65.

Le Houérou, H. N. (1993): Land degradation in Mediterranean Europe: Can agroforestry be part of the solution? A prospective review. Agroforestry Systems, 21: 43-61.

Le Houérou, H. N. y Hoste, C. H. (1977): Rangeland production and annual rainfall relations in the Mediterranean basin and in the African sahelo-sudarian zone. Journal Range Management, 30 (3): 181-189.

Lenclud, G. y Pernet, F. (1978): Ressources du milieu, gestion du troupeau et évolution sociales: les cas de la Corse. Etudes Rurales, 71-72: 49-87.

Lesorogol, C. K. (2003): Transforming institutions among pastoralist: Iniquality and land privatization. American Anthropologist, 105: 3531-3542.

Mahat, T. B. S., Griffin, D. M. y Shepherd, K. R. (1987): Human impacts on some forest of the Middle Hills of Nepal. Part 3: Forest in the subsistence economy of Sindhu Palchok and Kabhre Palan Chok. Mountain Research and Development, 7 (1): 53-70.

Mallet, M. (1978): Agriculture et tourisme dans un milieu haute-alpin: un exemple bianconnais. Etudes Rurales, 71-72: 111-154.

Matley, I. (1968): Transhumance in Bosnia and Herzegovina. Geographical Review, 58: 231-261.

Margalef, R. (1970): Explotación y gestión en ecología. Pirineos, 98: 103-121.

Mcnaughton, S.J. (1985): Ecology of a grazing ecosystem: The Serengueti. Ecological Monograph, 55: 259-294.

Mcnaughton, S. J. (1986): On plants and herbivores. The American Naturalist, 128: 765-770.

Merlino, R. J. y Rabey, M. A. (1983): Pastores del altiplano andino meridional: religiosidad, territorio y equilibrio ecológico. Allpanchis, 21: 149-171.

Metailie, J. P. (1984): La forêt paysanne dans les Pyrénées Centrales. Revue Géographique des Pyrénées et du Sud-Ouest, 55 (2): 231-238.

Milchunas, D. G., Lauentoth, Wk. y Burke, I. C. (1998): Livestock grazing: animal and plant biodiversity of shortgrass and relationship to ecosystem function. Oikos, 83: 65-74.

Milne, J. A. (1987). The grazing preferences of cattle. Sheep and goats for swads of different height. Annual Report of the Macaulay Land Use Research Institute: 89-90.

Millones, O. J. (1982): Patterns of land use and environmental problems of the Central Andes. An integral summary. Mountain Research and Development, 2 (1): 49-61. 
Molinillo, M. (1993): Its traditional pastoralism the cause of erosive processes in mountain environments? The case of the Cumbres Calchaquíes in Argentina. Mountain Research and Development, 13 (2): 189-202.

Molinillo, M. y Monasterio, M. (1997): Pastoreo y conservación en áreas protegidas de la Cordillera de Mérida, Venezuela. En: Desarrollo Sostenible de Ecosistemas de Montaña: Manejo de Areas Frágiles en los Andes (M. Liberman y C. Baied, eds.). UNU, Instituto de Ecología- UMSA, 93-109, La Paz (Perú).

Molinillo, M. y Monasterio, M. (1997a): Pastoralism in paramo environments. practices, forage, and vegetation impact in the Cordillera of Merida, Venezuela. Mountain Research and Development, 17: 595-609.

Molinillo, M. y Monasterio, M. (2001): Uso del espacio en sistemas pastorales andinos: una comparación mediante sistemas de información geográfica y evaluación multicriterio. IV Simposio Internacional de Desarrollo Sustentable en Los Andes. La estrategia Andina para el siglo XXI. Universidad de los Andes, Mérida.

Molinillo, M. y Monasterio, M. (2002): Patrones de vegetación y pastoreo de Páramo. Ecotrópicos, 15(1): 19-34.

Molinillo, M. y Monasterio, M. (2006): Vegetation and grazing patterns in Andean environments: a comparison of pastoral systems in Punas and Páramos. In: Land use change and mountain biodiversity (E. Spehn, M. Liberman and C. Korner, Eds). CPR, Boca Ratón, FL: 137-151.

Monasterio, M., ed. (1980): Estudios ecológicos en los páramos andinos. Universidad de los Andes, Mérida (Venezuela).

Monasterio, M. (1980): Poblamiento humano y uso de la tierra en los altos Andes de Venezuela. En: Estudios Ecológicos en los Páramos Andinos (M. Monasterio, Ed.). Universidad de los Andes: 170-198, Mérida.

Montalvo, J., De Miguel, J. M., Schmitz, M. F., García-Criado, B. y Pineda, F. D. (1988): Calidad de la hierba y sucesión secundaria en un pastizal mediterráneo. Monografías del Instituto de Pirenaico de Ecología, 4: 837-846.

Montalvo, J., Casado, M. A., Levassor, C. y Pineda, F. D. (1993): Species diversity patterns in Mediterranean grasslands. Journal of Vegetation Science, 4: 213-222.

Montoya, J. M. (1984): Pastoralismo mediterráneo. Monografías INIA, 25: 162 pp., Madrid.

Montserrat, P. (1964): Ecología del pasto. Publicaciones del Centro Pirenaico de Biología Experimental, 1: 22 pp., Jaca.

Montserrat, P. (1972): Estructura del sistema agropecuario. Anales de Edafología y Agrobiología, 31 (1-2): 151-156.

Montserrat, P. (1976): Aspectos relacionados con la investigación en praticultura y ganadería. Anales del Instituto de Estudios Agropecuarios, 2: 63-84.

Montserrat, P. (2008): Ecología del pasto pirenaico. Un panorama general. En: Pastos del Pirineo (F. Fillat, R. García-González, D. Gómez y R. Reiné, Eds). CSIC y Diputación de Huesca: 1-4, Huesca. 
Montserrat, P. y Fillat, F. (1977-78). La ganadería extensiva y las culturas rurales montañesas. Anales del Instituto de Estudios Agropecuarios, 3: 83-120.

Montserrat, P. y Fillat, F. (1990): The systems of grassland management in Spain. In: Managed Grasslands in Ecosystems of the World (A.I. Breymeyer, Ed.). 37-70, Amsterdam, Oxford, New York and Tokyo.

Montserrat, P. y Fillat, F. (2004): Pastos y ganadería extensiva. Evolución reciente de la ganadería extensiva española y perspectivas. XLIV Reunión de la S.E.E.P.: 9-17, Salamanca.

Montserrat-Martí, J. (1992): Evolución glaciar y postglaciar del clima y la vegetación en la vertiente sur del Pirineo: estudio palinológico. Monografías del Instituto Pirenaico de Ecología, 6: 149 pp., Jaca.

Morand-Fehr, P. y De Simiane, M. (1977): L'alimentation de la chèvre. Symposium sobre la cabra en los países mediterráneos.

Morley, F. H. W. (1981): Management of grazing systems. En: World Animal Science. Vol B-1: Grazing Animals. Elsevier: 179-400, Amsterdam.

Narjisse, H. (1990): Les resources sylvo-pastorales en milieu méditerranéen. In: L'élevage dans les systèmes cerealières méditerranéens (H. Narjisse y A. Kabbli, eds.). Pudoc, 353-393, Wageningen (Netherland).

Naveh, Z. y Kutiel, P. (1990): Changes in the Mediterranean vegetation of Israel in response to human habitation and land use. In: The Earth in Transition: Pattern and Processes of Biotic Improverishment (Woodwell, G. M., ed.). Cambridge University Pres, 259-299, Cambridge (U.K.).

Naveh, Z. y Whittaker, R. H. (1979): Structural and floristic diversity of shrublands and woollands in northern Israel and other Mediterranean areas. Vegetatio, 41 (3). 171-190.

O'connor, K. F. (1978): The rational use of high mountain resources in pastoral systems. In: The use of high mountains of the World. IUCN: 169-183, New Zealand.

O'connor, K. F. (1984): Stability and unstability of ecological systems in New Zealand mountains. Mountains Research and Development, 4 (1): 15-29.

Orlove, B. (1982): Native Andean pastoralist: traditional adaptations and recent changes. In: Contemporary Nomadic and Pastoral Peoples: Africa and Latin America (P.C. Salzman, ed.). College of William and Mary, 95-136, Williamsburg.

Osmaton, M. (1985): The productivity of the agriculture and pastoral system in Zangskar (M. N. Himalaya). Acta Biológica Montana, 5: 75-89.

Osoro, K. (1990): Recientes avances y futuro de la investigación en el manejo de los sistemas pastorales en zonas húmedas. XXX Reunión Científica de la S.E.E.P., 309360, San Sebastián.

Pallaruelo, S. (1988): Pastores del Pirineo. Ministerio de Cultura, 230 pp., Madrid.

Pallaruelo, S. (1993): Cuadernos de la trashumancia, $n^{o}$ 6: Pirineo aragonés. ICONA, 75 pp., Madrid. 
Pérez, R. y Díaz-Fierros, F. (1988): Resistencia del suelo y susceptibilidad a la compactación en terrenos de monte sometidos a pastoreo. Anales de Edafología y Agrobiología, XLVII (3-4): 547-560.

Perevolotsky, A. y Seligman, N. G. (1998): Role of grazing in Mediterranean rangeland ecosystems. Biocience, 48: 1007-1017.

Pineda, F. D. (2004): Procesos de intensificación agrícola, abandono de áreas rurales y conservación de la naturaleza en España. En: Medidas agroambientales y sistemas ganaderos en Europa. Su contribución a la conservación de los paisajes culturales. Consejería de Agricultura y Pesca, Junta de Andalucía, 17-35, Sevilla.

Postigo, J. C., Young, K. R. y Crews, K. A. (2008): Change and continuity in a pastoralist community in the High Peruvian Andes. Human Ecology, 36: 535-551.

Price, L. W. (1981): Mountain and Man. A study of process and environment. University of California Press, 506 pp., London.

Puigdefábregas, J, y Fillat, F. (1986): Ecological adaptation of traditional land-uses in the Spanish Pyrenees. Mountain Research and Development, 6 (1): 63-72.

Puigdefábregas, J. y Balcells, E. (1970): Relaciones entre la organización social y la explotación del territorio en el valle del Roncal (Navarra Oriental). Pirineos, 98: 53-89.

Puigdefábregas, J. y Mendizábal, T. (1998): Perspectivas on desertification: Western Mediterranean. Journal of Arid Environments, 29: 209-224.

Reffay, A. (1967): Vie pastorale d'une moyenne montagne: le Chablais. Revue de Géographie Alpine, 73(3): 297-312.

Rinschede, G. (1988): Trashumance in European and American mountains. In: Human impact on mountains (N. Allan, G. Knapp and C. Stadel, Eds). Roman \& Littelfield: 96-108, Totawa, New Jersey.

Rodríguez Pascual, M. y Maya Frades, A. (2008): Los puertos y la trashumancia en los valles leoneses de Sajambre y Valdeón: Tradición y perspectivas de futuro. Universidad de León. Colección: Conocer León: 143 pp., León.

Ruiz, M. (2004): Fundamentos ecológicos y económicos para la práctica de la trashumancia en España. En: En: Medidas agroambientales y sistemas ganaderos en Europa. Su contribución a la conservación de los paisajes culturales. Consejería de Agricultura y Pesca, Junta de Andalucía, 57-61, Sevilla.

Ruiz, M, y Ruiz, J. P. (1986): Ecological history of trashumance in Spain. Biological Conservation, 37: 73-86.

Shaoliang, Y., Ning, W., Peng, L., Qiam, W., Fusum, S., Geng, S. y Jianzhong, M. (2007): Changes in livestock migration patterns in a Tibetan-style agropastoral system. A study in the Three-parallel-rivers region of Yunnan, China. Mountain Research and Development, 27 (2): 138-145.

Semmartin, M. y Oesterheld, M. (1996): Effect of grazing pattern on primary productivity. Oikos, 75: 431-436.

Serrate, C. (1977): Quelques aspets de l'évolution morphologique de versant d'adrêt de la Tête Noire de Galibier. Rechearches en Brianconnais, 5: 107-137. 
Sierra, I. (1994): Las razas autóctonas y la conservación de recursos genéticos. Congreso Mundial de Razas Autóctonas y Criollas. 35 pp., Cajamarca, Perú.

Sierra, I. (1996): Los sistemas extensivos, las razas autóctonas y el medio natural. XXXVI Reunión de la S.E.E.P., 17-31, Logroño.

Sierra, I. (2002): Análisis y perspectivas de las estructuras y sistemas de producción ganaderas en Aragón. Libro Blanco de la Agricultura y el Desarrollo Rural. MAPA: 1-42, Vitoria.

Stone P. B., ed. (1992): The state of the world's mountains. A global report. Zed Books Ltd. London \& Now Jersey.

Thorez, P. y Reparaz, A. de (1987): La population et le peuplement dans le Caucase Oriental et dans les Alpes du Sud. Formes traditionnelles, formes contemporaines, différenciations régionales. Méditerranée, 2-3: 95-110.

Thornes, J. (2007): Modelling soil erosion by grazing. Recent developments and new approaches. Geographical Research, 45 (1): 13-26.

Tucker, R. P. (1987): Dimensions of deforestation in the Himalaya: the historical setting. Mountain Research and Development, 7 (3): 328-331.

Uhlig, H. (1995): Persistence and change in higt mountain agricultural systems. Mountain Research and Development, 15 (3): 199-213.

Vargas, O., Premauer, J. y Cárdenas, C. A. (2002): Efecto del pastoreo sobre la estructura de la vegetación en un páramo húmedo de Colombia. Ecotrópicos, 15 (1): 35-50.

Vicente-Serrano, S., Lasanta, T. y Cuadrat, J. M. (2000): Influencia de la ganadería en la evolución del riesgo de incendio en función de la vegetación de un área de montaña: el ejemplo del valle de Borau (Pirineo aragonés). Geographicalia, 38: 33-58.

Vicn (1978): The use of high mountains of the world. Conference on the Conservation of Higt Mountain Resources. New Zealand.

Villar, L. y García-Ruiz, J. M. (1977): Explotación del territorio y evolución de pastos en dos valles del Pirineo occidental. Publicaciones del Centro Pirenaico de Biología Experimental, 8: 143-163.

Vos, M. y Meekes, H. (1999): Trends in European cultural landscape developement: perspectives for a sustainable future. Landscape and Urban Planning, 46: 3-14.

Yasuda, H. (1958): Transhumance. Geography, 3 (10): 54-58.

White, S. y Maldonado, F. (1991): The use and conservation of natural resources in the Andes of Southern Ecuador. Mountain Research and Development, 11: 37-55.

Williamson, G. B., Schatz, G. F, Alvarado, A., Redhead, C. S., Stam, A. C. y Sterner, S. W. (1986): Effects of repeated fire on tropical paramo vegetation. Tropical Ecology, 27: 62-69.

Zorita, E. (1990): Hacia una nueva estrategia de la ganadería ovina en España, armonizando recursos alimenticios y objetivos medioambientales. Ovis, 11: 9-42.

Zhao, H. L., Zhao, X. Y., Zhou, R. L., Zhang, T. H., y Drake, S. (2005): Desertification processes due to heavy grazing in sandy rangeland, Inner Mongolia. Journal of Arid Environments, 62: 309-319. 


\title{
RESUMEN
}

Las montañas constituyen áreas preferentes para la localización de la ganadería extensiva basada en el pastoreo de recursos naturales, por lo que existe una bibliografía muy abundante sobre pastoralismo: integración entre pastizales y pastoreo. En este trabajo se realiza una revisión bibliográfica sobre la vinculación del pastoralismo a las áreas de montaña, utilizando fundamentalmente la base de datos Scopus. Se insiste en las estrategias de pastoreo (nomadismo, trashumancia y agropastoreo), sus impactos sobre el medio (densidad y estructura de la vegetación, erosión del suelo,...) y en el papel de las razas autóctonas y la complementariedad entre especies ganaderas en el aprovechamientos de los pastos y la conservación de los recursos naturales. Se finaliza el trabajo apuntando algunos cambios recientes en el pastoreo de montaña.

PAlabras ClAVE: pastoreo; estrategias de pastoreo; impacto del pastoreo; pastizales; montaña.

\begin{abstract}
Mountains represent preferent areas for extensive livestock based on natural resources, and therefore a large amount of scientific literature dealing with pastoralism and the integration between grassland and livestock grazing. The present article provides a bibliographical review about pastoralism in mountain areas, using Scopus database as main data source. Pastoral strategies (nomadism, trashumance and agropastoralism), its impacts on the environment (density and structure of vegetation, soil erosion...), the role of local breeds and complementarities between different cattle types are emphasized in this review. This article underlines recent changes in mountain pastoralism.
\end{abstract}

KEY WORDS: pastoralism; pastoral strategies; grazing impact; grassland; mountain.

\section{RÉSUMÉ}

Les montagnes constituent des aires très convoitées pour l'élevage extensif basé sur le pâturage des ressources naturelles, de ce fait que la bibliographie sur le pastoralisme, la relation entre les formations pâturées d'altitude et le pâturage, est abondante et pluridisciplinaire. Cet article présente une révision bibliographique sur le lien entre le pastoralisme et les montagnes, en utilisant la base de données Scopus comme source fondamentale d'information. Nous traitons des stratégies pastorales (nomadisme, transhumance et agro-pastoralisme), des impacts du pâturage sur le milieu (densité et structure de la végétation, érosion du sol...), du rôle des races autochtones, et de la complémentarité entre les espèces de bétail et l'usage des pâturages ainsi que la conservation des ressources naturelles. Finalement, nous nous attarderons sur quelques changements récents du pastoralisme montagnard.

MOTS CLÉS: pastoralisme; stratégies pastorales; impact du pâturage; formations pâturées; montagne. 